\title{
A produção de informação em Brasília: os bastidores da política no blog da jornalista Andréia Sadi
}

\section{Paula de Souza Paes}

Doutora; Universidade Estadual de Ponta Grossa, Ponta Grossa, PR, Brasil paulasouzapaes@gmail.com

\section{Karina Janz Woitowicz}

Doutora; Universidade Estadual de Ponta Grossa, Ponta Grossa, PR, Brasil karinajw@gmail.com

\section{Resumo}

O trabalho é resultado parcial do estágio de pós-doutorado de uma das autoras, com o objetivo de estudar a produção de informação política nos blogs brasileiros. A investigação deu-se por meio da análise de artigos publicados no blog da jornalista Andréia Sadi, repórter da GloboNews. A análise corresponde a 198 publicações durante três meses (fevereiro, março e abril) de 2017. Com o objetivo de compreender e caracterizar as relações de interdependência entre jornalistas especializados em política e políticos, o artigo apoia sua argumentação em um paradoxo à primeira vista: a visibilidade crescente do jornalismo político principalmente, a partir da emergência de blogs jornalísticos - e o desprestígio da informação política revelado por recomposições que afetam tanto o campo político quanto o jornalístico. Entre os resultados observados, destacam-se o peso das estratégias de comunicação das assessorias, notícias que privilegiam o "jogo" político entre "direita" e "esquerda". Ainda, a ausência de reflexão sobre a política, uma vez que a informação produzida corresponde essencialmente, às diferentes reações dos "adversários" políticos.

\section{Palavras-chave}

Informação política. Jornalistas políticos. Blog. Weblog. Globonews. 


\section{Introdução}

Considerada editoria nobre do jornal, a política é tratada, atualmente, por vários jornalistas considerados "especializados", que se utilizam da plataforma blog. Tido como precursor de blog de cobertura política, o jornalista Ricardo Noblat é um exemplo dessa dinâmica ${ }^{1}$. Com a emergência da web e dos jornais em sites, esse movimento foi impulsionado e, por meio dos blogs, não só o jornalismo digital vem sendo repensado, mas também a própria definição de informação política. Ao hospedar blogs em seus sites, os jornais tradicionais reconhecem a sua importância no processo de produção de informação. O blog é uma ferramenta caracterizada pela diversidade e pela dinâmica de produção, práticas e atores. Interessa nesse artigo, particularmente, analisar como os blogs vêm sendo utilizados por jornalistas profissionais que tratam política, como é o caso da jornalista Andréia Sadi. Ela mantém, assim como outros profissionais da Globo News, um blog com seu nome (SADI, c2018) no G1, portal pertencente ao grupo Globo.

Na pesquisa, o objetivo é observar a informação política produzida em um blog político "especializado" e nas possíveis transformações na maneira de tratar a política. Esse recorte torna-se ainda mais pertinente se considerarmos que pesquisadores reiteram a transformação pela qual a produção de informação sobre política passou - e tem passado no Brasil e em países europeus. Pesquisas abordam a perda de prestígio da informação política e o tratamento fait divers dado a ela por meio da busca pelo sensacional, devido ao peso da lógica comercial (que se baseia na falta de interesse dos indivíduos nas questões políticas) e, também, profissional. Isto aplica-se tanto à política interna quanto externa (SENNE, 2009; MARCHETTI, 2005). Esse movimento revela, assim, recomposições que interferem nos campos políticos e jornalísticos e, portanto, mutações que afetam a esfera pública. Essas mudanças explicam-se, entre outros fatores, pelas relações de proximidade entre jornalistas e políticos.

Sendo um espaço para a prática de um jornalismo especializado, o blog é, também, um espaço de questionamento das ações públicas? 0 artigo parte dessa pergunta, tentando desconstruir a visão normativa de que jornalistas e políticos encontrariam-se em posições opostas no espaço social. Como salienta o professor em ciências políticas, Erik Neveu (2003), as autoridades políticas e jornalistas estabelecem uma rede de interdependência. Essa configuração alimenta-se da crença no "poder" de comunicação e seu impacto sobre o público, o que se reforça diante de mudanças, tais como o desinteresse pela política, a baixa

\footnotetext{
1 O Blog do Noblat (NOBLAT, 2018) existe desde 2004 e já foi objeto de estudo de algumas pesquisas no Brasil (LIMA, 2015).
} 
atratividade dos programas políticos, a falta de confiança no Estado etc. Essas transformações são entendidas pelos responsáveis políticos como o resultado de uma falta de comunicação, suscitando dessa forma estratégias de interdependência junto ao campo jornalístico. Essa tendência revela comportamentos de antecipação nos atores políticos (como aparecer no noticiário da televisão ou em anúncios em conferências de imprensa, por exemplo), remodelando o métier político.

0 período de análise corresponde aos 3 meses do ano de 2017 que estão disponíveis online, a saber: fevereiro, março e abril. A jornalista escreve, em média, artigos por dia, incluindo sábado e domingo. Além de ser interessante analisar um blog de uma jornalista que cobre política - uma vez que é pequena a representatividade feminina em blogs, principalmente, no jornalismo político ${ }^{2}$ - outros elementos chamaram a atenção no decorrer da pesquisa. Os blogs do grupo Globo figuram nas manchetes dos sites G1 e Globo.com. Dessa forma, pode-se perceber que as notícias apuradas pelos blogs dos jornalistas da empresa repercutem no jornal. Eles fazem parte, portanto, da linha editorial do veículo. Além disso, a análise do blog de uma jornalista de TV permite entender como se dá a repartição de tarefas e o estabelecimento de fronteiras profissionais entre o site e o canal de televisão.

Embora o corpus limite-se ao blog político de uma jornalista da Globo, sua escolha justifica-se pela importância que ele apresenta no contexto midiático brasileiro: os escândalos políticos recentes foram noticiados, primeiramente, por blogs dessa mesma empresa como, por exemplo, o blog do jornalista Gerson Camarotti e a divulgação de áudios envolvendo o presidente da República Michel Temer e empresários em maio deste ano. Além disso, a organização conta com um canal que veicula apenas notícias sobre política, a GloboNews, o que explica, portanto, nossa escolha.

Dessa forma, o artigo pretende aprofundar a relação entre a empresa e o blog de política mantido pela jornalista. Esse recorte justifica-se pelo fato de que vários trabalhos de pesquisadores brasileiros demonstram a relação entre a visibilidade do jornalismo político (principalmente a partir da emergência de blogs jornalísticos) e os escândalos de corrupção que envolveram os responsáveis políticos entre os anos 1990 e 2000 (GUAZINA, 2013; ALDE; ESCOBAR; CHAGAS, 2007). Esse movimento foi também observado em outros países, como nos Estados Unidos, por exemplo, nas eleições presidenciais de 2004 quando a

2 Sobre o tema, fazemos referência a Lima (2015), mesmo que o objetivo da tese da autora não tenha sido analisar os blogs de jornalistas mulheres. 
imprensa norte-americana repercutiu informações políticas que foram publicadas em blogs (QUADROS; ROSA; VIEIRA, 2005). No Brasil, a partir das eleições de 2006 e 2010, os blogs políticos, principalmente os de portais de veículos noticiosos tradicionais, passam a ser analisados (CARVALHO, 2016). Entretanto, o interesse aqui se restringe a um blog de uma jornalista profissional que é vinculada a uma empresa jornalística.

Sendo assim, o artigo procura responder as seguintes perguntas: Como a jornalista que esta inserida em uma empresa midiática apropria-se do blog? Existe maior independência do blog em relação à organização midiática? Existe mais transparência na apuração? Busca de novas fontes? A proposta não é analisar o blog como espaço de discussão política. Apesar de terem sido repertoriados, os comentários não foram objeto de análise. 0 objetivo é compreender as mutações que essa relação envolve e revela sobre a produção de notícias sobre política propriamente dita e as possíveis dissonâncias entre o fazer jornalístico e sua relação com a política e o interesse público. Para responder essas perguntas, foram estabelecidas 3 categorias para a análise das 198 publicações do blog durante os meses de fevereiro, março e abril de 2017: a produção própria realizada pela jornalista para o blog; os interlocutores citados nos textos; e a compreensão dos temas tratados pela jornalista como "político". Esses elementos serão aprofundados ao longo do texto.

\section{Jornalismo e blog}

As novas rotinas dos profissionais da mídia e as modalidades de expressão pública (dispositivos participativos, debates públicos, blogs) inscrevem-se em um contexto industrial avançado que força as organizações midiáticas a revisitar os seus modelos econômicos e editoriais. Face a reestruturação da imprensa escrita e chegando para reforçar esse movimento, desenvolve-se a imprensa escrita online. Ela potencializou um processo de mudança que já poderia ser observado no jornalismo impresso (NEVEU, 2010).

0 jornalismo na internet - webjornalismo ou jornalismo online - indica reconfigurações nas rotinas de produção com a integração entre mídia impressa e online. A criação de sites, portais e blogs pelas empresas jornalísticas brasileiras e em diversos países aparecem como novas oportunidades de interação entre os profissionais da mídia e seus leitores. Os blogs ou weblogs ${ }^{3}$ - objeto que interessa aqui - são ferramentas que com a

3 Para uma análise detalhada sobre as histórias e filiações do termo weblogs, indicamos Le Cam (2010). 
emergência e o desenvolvimento da web, foram objeto de investimento pelas empresas jornalísticas, seja incentivando o uso pelos seus próprios jornalistas, seja pelos seus leitores ou pessoas interessadas em escrever. Assim, os blogs são mantidos por jornalistas e jornalistas exteriores à empresa midiática, especialistas em web, impresso, fotografia, política, esporte e atores "não jornalistas".

Esses elementos não só chamam a atenção para as mudanças que afetam áreas de jornalismo tradicional, mas também podem instigar os pesquisadores a questionar outros espaços e formas de legitimidade jornalística e como esses espaços atuam na produção de informação. 0 blog jornalístico não esbarra em um problema de legitimidade, visto que é produzido por profissionais, como exemplifica o blog da jornalista Andréia Sadi.

A grande quantidade de publicações, categorizações e levantamentos sobre weblogs demonstra a "popularidade" desse tema no Brasil e em outros países (LE CAM, 2010; DOMINGO; HEINONEN, 2008). Essa visibilidade é ainda maior quando se relaciona os blogs ao jornalismo. Muitos estudos abordam o processo de edição, distribuição de notícias em blogs jornalísticos no Brasil e, principalmente, as possíveis transformações que essa relação trouxe para o exercício do jornalismo e suas potencialidades (SATUF, 2008).

As relações entre jornalismo e blog se deram principalmente por meio de dois momentos, segundo a pesquisadora Florence Le Cam (2010) que realizou um estudo sobre os weblogs e as perspectivas para pensar a história do objeto "weblog". Um primeiro momento do reconhecimento midiático dos blogs vem de jornais internacionais The New York Times e The Guardian que começam a propor, no final dos anos 90 e começo dos anos 2000, weblogs aos leitores e, no caso inglês, um blog especializado em informação internacional. Uma segunda forma pública de reconhecimento se dá por meio de acontecimentos na atualidade internacional (não só no 11 de setembro de 2001, mas também nos atentados em Londres, no Tsunami de 2004, etc.). No Brasil, um blog diário chamado Diário de Bagdá criado por jornalistas da Folha de S. Paulo, em 2003, é considerado uma experiência precursora na história do blog jornalístico do país, uma vez que se tornou a primeira experiência oficial brasileira de cobertura jornalística realizada por meio de um blog (FOLETTO, 2009). A partir dessa data, os blogs são incorporados à prática profissional jornalística brasileira por meio da produção de informações especializadas em guerras. Esse movimento potencializa a atuação dos weblogs junto à atividade jornalística.

É possível acrescentar a esse contexto outras iniciativas internacionais que revelam a relação dos blogs com o jornalismo online. É o que demonstra os blogs internacionais 
voltados para a temática política e o factchecking: Les Décodeurs foi criado pelo jornal francês Le Monde, em 2009, para identificar, a partir da análise de discursos políticos, as verdades e as mentiras contadas pelas autoridades públicas. Esse blog acabou tornando-se uma editoria fixa no jornal (SALLES, 2016). Outro exemplo é o blog Le Désintox (2018) do jornal francês Libération, lançado pelo site Libération.fr, que também tem por objetivo analisar discursos políticos. Ele se tornou uma editoria no jornal impresso. Os jornalistas do Brasil passaram a investir no chamado fact checking, uma tendência do jornalismo político online. O blog É isso mesmo? (O GLOBO, c2018) é um exemplo. Dessa forma, podemos perceber como os jornais online investem em iniciativas "originais" na web e utilizam-se do blog para isso. Ademais, elas são voltadas para a produção de informação política especializada.

Sendo assim, para além de uma análise sobre os possíveis "impactos" ou renovações do blog para o jornalismo, a proposta parte da seguinte perspectiva: o blog é aqui considerado como uma ferramenta que contribuiu para mudanças que já vinham acontecendo nas redações das mídias tradicionais e seu processo de adaptação ao digital. Entendemos a criação de blogs pelas empresas jornalísticas como uma oportunidade, ou seja, uma estratégia de fidelizar os leitores e de se adaptar às novas maneiras de consumo da informação. Portanto, pretende-se distanciar de uma abordagem técnico-determinista (MIÈGE, 2009) que consistiria em considerar apenas as potencialidades dadas por uma técnica (ou tecnologia) sem questionar as relações de poder que ela também revela.

0 que nos interessa, portanto, nesse artigo, é compreender a produção de informação política e, de que maneira, ela revela estratégias profissionais de disputa por credibilidade. 0 termo estratégias é aqui entendido no sentido bourdieusiano. Segundo o sociólogo francês, Pierre Bourdieu (2002), as estratégias são ações estabelecidas de acordo com os interesses dos atores e orientadas para objetivos específicos. No entanto, as ações não devem ser entendidas como ações definidas para fins "expressamente concebidos" para alcançar um objetivo. Elas se referem a modos de luta, relações de poder na produção de informações.

No caso do jornalismo político, essa disputa tenciona ainda mais a prática jornalística, uma vez que os jornalistas de política têm por objetivo acompanhar o dia a dia dos deputados e senadores eleitos, o funcionamento das instituições e da democracia. A credibilidade do jornalismo constitui-se, portanto, 
[...] a partir do cruzamento da autoridade das fontes consultadas e de uma autoridade própria, amparada em sua competência especializada e em métodos confiáveis de construir um relato polifônico e equilibrado. Ocorre uma transferência mútua de credibilidade, que ajuda a construir a reputação da instituição jornalística. (LISBOA; BENNETTI, 2015, p. 21)

No caso brasileiro, o sentimento de responsabilidade social é ainda mais evidente nos jornalistas políticos. 0 jornalismo político indica o esforço dos profissionais de reiterarem seu papel no espaço social por meio da constituição de um grupo delimitado. A prática jornalística no Brasil (assim como em outros países) debruça-se sobre valores de independência, autonomia e defesa do interesse público (KARAM, 2004; RUELLAN, 1997). Esse sentimento fica ainda mais evidente, se for levado em conta que a desconfiança está entre os valores mais característicos da cultura política dominante nesse país (GUAZINA, 2015).

É importante salientar, como aponta Pereira (2015), o midiacentrismo das pesquisas realizadas no Brasil sobre as relações entre mídia e política. Como aponta o pesquisador brasileiro, existe uma lacuna nos estudos sobre as relações que os jornalistas tecem com seus interlocutores. Essa observação faz-se ainda mais importante tendo em vista que a produção de informação fora do espaço jornalístico cresce constantemente e que as fontes tornaram-se "verdadeiras organizações políticas" (PEREIRA; ADGHIRNI, 2011, p. 47). Sendo assim, esse artigo tem um interesse particular pelos interlocutores consultados pela jornalista, como explicaremos em seguida.

\section{A produção de informação}

Antes de apresentar a análise do blog propriamente dito, alguns elementos de contextualização sobre ele devem ser abordados. 0 blog da Andréia Sadi é relativamente recente: em 2015, ela passou a integrar a equipe de política da Globo News em Brasília, depois de diferentes experiências em jornais tradicionais como a Folha de S. Paulo, no qual produzia reportagens sobre a temática política e os bastidores da política. Segundo a descrição do seu blog, ela publicou na Folha, "[...] a primeira reportagem envolvendo um político na Operação Lava Jato." (G1, 2017, doc. não paginado). Pelo site do G1, pode-se ter acesso às postagens publicadas a partir de fevereiro de 2017. Os principais temas abordados no período de análise (fevereiro a abril) foram: denúncias envolvendo deputados, senadores e o Presidente; nomeação de deputados, tramitação de projetos de lei ou propostas, votos da classe política em relação a julgamentos, visitas realizadas pelo Presidente ou para ele e; por 
fim, - e sobretudo - escândalos políticos (delações premiadas envolvendo o caso Odebrecht). É importante salientar que a jornalista não se pronuncia em primeira pessoa, como fazem outros jornalistas blogueiros, como Leonardo Sakamoto. Contudo, isso não significa que suas reportagens ou notícias não apresentem orientações políticas. Como veremos a seguir, o blog tende a reiterar a visão das fontes oficiais, colocando em debate o papel social da profissão e a própria identidade do grupo de profissionais da mídia (RUELLAN, 1997).

A análise do blog realizou-se a partir de três eixos principais: o primeiro diz respeito ao conteúdo do blog que teve por objetivo separar a produção própria do blog de outras citadas pela jornalista. $\mathrm{O}$ foco era perceber a legitimidade e sua autonomia em relação à Globo News, no qual Andréia Sadi é repórter. 0 reconhecimento profissional passa pela legitimidade do trabalho de coleta de informaçoes in loco e pelas trocas com as fontes.

Examinar a produção de informação implica analisar as interações entre os profissionais da mídia e seus interlocutores (SCHLENSINGER, 1992). Sendo assim, o segundo eixo foi estabelecido para entender a relação com as fontes: quem fala? Quem tem direito de fala? Portanto, foram repertoriados os principais interlocutores citados. A legitimidade de um jornalista e sua credibilidade estão relacionadas à "boa" escolha das fontes. A regra de polifonia é umas das regras fundadoras da prática do jornalismo. Como descreve Cyril Lemieux (2000, p. 372, tradução nossa):

A polifonia, como a entendemos aqui, é, portanto, esta regra da escrita jornalística moderna que quer que, na presença de um conflito de interpretações, sejam organizadas, no mesmo discurso ou na mesma transmissão, visões divergentes, às quais o jornalista tende a conceder um status de equivalência a priorit.

Entretanto, os jornalistas sempre fazem escolhas: as fontes nao têm o mesmo peso, ou seja, cada interlocutor escutado pela jornalista é o resultado de uma escolha que indica a linha editorial do blog.

0 terceiro eixo focalizou-se na informação política em si, buscando compreender de que forma a temática política é abordada em seus textos. Uma atenção particular foi dada às "estratégias de ação" da jornalista, inspirada na pesquisa considerada percursora de Jean Gustave Padioleau (1976) que revelou a importância da especialização dos jornalistas em determinadas temáticas em relação à seleção e à hierarquização das situações. As

\footnotetext{
4 No original: La polyphonie, telle que nous l'entendons ici, c'est donc cette règle de l'écriture journalistique moderne qui veut qu'en présence d'un conflit d'interprétations, soient agencées, dans un même discours ou une même émission, des prises de position divergentes, auxquelles le journaliste tend à accorder un statut d'équivalence a priori.
} 
estratégias são essencialmente duas: a objetividade por meio do distanciamento da jornalista em relação aos fatos e às declarações; e a expertise crítica que consiste no esforço da jornalista em buscar contextualizar os fatos (as causas, as consequências, os posicionamentos dos diferentes atores em relação a um fato).

A prática jornalística é atravessada por uma lógica de explicação e justificação (BERGER; LUCKMANN, 2012) do profissionalismo que ganha sentido não só em um discurso que visa julgar as situações que nos são comuns, mas também em discursos que visam apresentar os valores morais dessa profissão, tornando os jornalistas confiáveis e permitindo-lhes ter o direito de falar sobre questões controversas. Dessa maneira, como afirma Aristóteles (2007, p. 24), “[...] os meios de persuasão não dizem respeito apenas a um discurso demonstrativo". 0 orador depende da sua postura ética: ele deve mostrar que ele é benevolente. Assim, os jornalistas tentam ter a confiança e o crédito de seus leitores, não demonstrando a escolha política das empresas de mídia, pela justificativa das razões pelas quais determinado assunto é digno de reflexão e atenção. É essa justificativa que aparecerá na análise do corpus, primeiramente, pela afirmação do blog enquanto espaço legítimo de apuração e veiculação de notícia, que abordaremos agora.

\subsection{Legitimidade do Blog}

0 termo "blog" é citado, frequentemente, nas notícias: 42\% (84 vezes). Percebe-se, assim, um esforço da jornalista em reafirmar a plataforma como um lugar legítimo de produção de notícia. Além disso, percebe-se uma tendência de valorização do blog enquanto espaço do "furo" jornalístico; de interlocutor privilegiado pelos políticos e; enfim, do lugar da enquete jornalística, como mostra o quadro abaixo:

Quadro 1 - Autorreferenciamento no Blog da Andréia Sadi

\begin{tabular}{|c|c|}
\hline \multicolumn{2}{|r|}{ Papel do blog } \\
\hline $\begin{array}{c}\text { "Furo" } \\
\text { jornalístico }\end{array}$ & $\begin{array}{l}\text { - "A nova estratégia do Planalto, revelada pelo Blog" } \\
\text { - "Conforme antecipou o Blog na semana passada [...]" } \\
\text { - "O blog teve acesso à íntegra do depoimento [...]" }\end{array}$ \\
\hline $\begin{array}{l}\text { Interlocutor } \\
\text { privilegiado } \\
\text { pelos políticos }\end{array}$ & $\begin{array}{l}\text { - } \quad \text { "Ao Blog, o presidente responde [...]" } \\
\text { - "O principal motivo, segundo parlamentares disseram ao blog [...]" } \\
\text { - } \quad \text { "O presidente do Senado, Eunício Oliveira (PMDB-CE), disse ao blog [...]". }\end{array}$ \\
\hline $\begin{array}{l}\text { Lugar da } \\
\text { enquete } \\
\text { jornalística }\end{array}$ & $\begin{array}{l}\text { - } \quad \text { "O Blog perguntou" } \\
\text { - "O Blog apurou" } \\
\text { - } \quad \text { "Procurado pelo Blog" }\end{array}$ \\
\hline
\end{tabular}

Fonte: Elaborado pelas autoras, a partir de Sadi (c2018). 
De uma maneira geral, os jornalistas evocam, como garantia de profissionalismo, o desejo de compreender as experiências diárias por meio de métodos profissionais, como idas a campo e do contato com as pessoas. A afirmação do blog, enquanto interlocutor privilegiado pelos políticos e, também, lugar da enquete jornalística, é uma maneira de reafirmar esse profissionalismo. O jornalismo de enquete revela elementos como imediatismo e proximidade que são valorizados pelos profissionais (RUELLAN, 2007).

O blog faz referência, também, a outras mídias, principalmente, à Globo News ou ao Grupo Globo (Jornal Nacional, TV Globo, Blog do Lauro Jardim). Muitas vezes (em 49 notícias das 198 publicadas), a notícia é fruto de uma apuração complementar ao que foi divulgado por esse canal de televisão ou, ainda, apresenta apenas vídeos da aparição da jornalista na GloboNews, ou trechos de alguma entrevista que ela tenha feito para o canal em Brasília. Trata-se de mostrar proximidade com o tema do qual ela é considerada especialista. Portanto, na relação jornalista e seus leitores:

Não há apenas uma confiança no que é dito, mas também na figura de quem enuncia e neste compromisso moral que envolve a comunicação intersubjetiva. No caso do jornalismo, cujo principal objetivo é a comunicação de informações sobre o mundo, esse compromisso moral é ainda maior. 0 jornalista tem obrigações especiais de oferecer informações verídicas sobre eventos da atualidade para um público, de acordo com critérios de relevância e notabilidade, e o leitor o avalia com maior rigor do que avaliaria um taxista comentando a previsão do tempo (LISBOA; BENNETTI, 2015, p. 19).

Dessa forma, quando a jornalista apresenta o blog como um lugar legítimo, ela se apresenta, também, como uma profissional qualificada para desenvolver seu papel enquanto jornalista. No entanto, é importante frisar que a jornalista em questão trabalha para uma empresa convencionalmente considerada conservadora. Uma das razões que justifica essa característica é sua relação com as fontes.

\subsubsection{As fontes: uma interdependência estrutural}

Toda notícia publicada apresenta, ao menos, uma fonte, mesmo que a sua identidade completa seja indefinida ou não revelada, ou ainda, seja documental (relatórios, depoimentos de ministros ou ex-ministros). A não identificação das fontes é um fator que chama atenção na análise: dos 198 artigos publicados pela jornalista em seu blog, 89 ( 45\%) 
foram classificados como indefinidos, como mostra o quadro abaixo. As notícias assim classificadas revelam os seguintes termos: "aliados do presidente defendem"; "diz um interlocutor", "segundo um interlocutor", "Um interlocutor do presidente disse", "Dois ministros ouvidos pelo Blog defendem"...

Quadro 2 - Dados sobre as fontes citadas no Blog Andréia Sadi

\begin{tabular}{|c|c|c|c|c|}
\hline Fontes & Mídia & Assessoria & Advogados & Fonte indefinida \\
\hline Artigos & 49 & 36 & 17 & 89 \\
\hline Total & \multicolumn{3}{|c|}{198} \\
\hline
\end{tabular}

Fonte: Elaborado pelas autoras, a partir de Sadi (c2018).

Essa tendência demonstra dois pontos principalmente. Primeiramente, a cumplicidade da jornalista com as fontes, principalmente, as institucionais (políticos em geral e instituições públicas). Além disso, existe uma preocupação da jornalista em buscar notícias de bastidores: revelar o ambiente no Palácio do Planalto, os rumores, até mesmo, o senso de humor do Presidente5. Dessa maneira, ela opta por não expor sua fonte, contrariando um dos princípios básicos da prática jornalística, explícitos no Código de Ética dos Jornalistas Brasileiros (BRASIL, 2007).

Essa busca acaba revelando outra característica: o peso dos assessores na produção da notícia. A presença desses profissionais é tão evidente que, em muitos casos, é a única fonte ouvida pela jornalista. Foi o caso ocorrido no dia 21 de fevereiro de 2017, em que o MST tentou entrar no Ministério das Cidades, e a jornalista divulgou nota na íntegra do ministro responsável, sem ouvir o MST. Dessa forma, uma única versão é colocada em evidência, o que contraria o princípio de polifonia tratado acima.

Fábio Pereira (2015) demonstra em uma pesquisa o papel de assessores de imprensa, parlamentares, porta-voz e chefes de comunicação na cobertura política. A relação entre eles e a imprensa é de dependência. A interdependência entre assessores e jornalistas foi tratada também pelo pesquisador Jérémie Nollet (2006) que demonstrou como as decisões político-administrativas são submissas aos enquadramentos dominantes da mídia.

\footnotetext{
5 No dia 2 de fevereiro de 2017, Andréia Sadi publica uma notícia em que escreve: "O presidente anda tão irritado com as indicações para o STF que sobrou até para o marqueteiro.” (SADI, 2017b, doc. não paginado).
} 
A análise revela, também, que as declarações dos políticos ganham importância na apuração. Trata-se de apresentar as reações dos diferentes ministros e deputados, até o que eles dizem nas redes sociais é colocado em evidência. Frases como "O palácio do planalto afirmou..." e a divulgação de notas de assessoria caracterizam, também, as notícias publicadas pelo blog, sem nenhuma problematização da notícia. É possível, inclusive, questionar se o que foi publicado é realmente uma notícia, segundo os critérios de noticiabilidade, ou apenas anúncios que visam valorizar ações e discursos dos políticos.

A presença de advogados também é um ponto pertinente revelado pela análise. Como as notícias são compostas por declarações e reações dos políticos, os advogados aparecem na apuração para explicar o posicionamento de seus respectivos clientes. A presença desses atores reforça a tonalidade dominante presente nas notícias: os políticos são apresentados como "adversários", e a política, em si, é como um jogo que se estabelece entre ganhadores e perdedores. Segundo a filósofa Hannah Arendt (1995), a política não se trata de uma relação entre dominantes e dominados. Dessa forma, tudo indica que a produção de informação política pelo blog é baseada em relatos que tendem a desconflitualizar os problemas enfrentados pela sociedade, como veremos agora.

\subsection{Informação política: uma questão de jogo e estratégias}

Em relação à informação política propriamente dita, a análise demonstra que a jornalista mantém certa distância dos fatos por meio da reprodução das declarações dos políticos. Elas se resumem às reações dos políticos em determinadas situações, como, por exemplo, na nomeação de um novo ministro e na delação de acusados em crimes de corrupção. A agenda do Presidente é acompanhada pela jornalista: esse acompanhamento de "perto" da política, no cotidiano, é valorizado. É uma forma da jornalista se afirmar enquanto ator do debate público e, também, sua habilidade ou competência específica para tratar o tema. Algumas análises e previsões sobre as consequências de determinadas medidas são realizadas pela jornalista: percebe-se que ela conhece as regras que regem as decisões da Câmara e do Senado. Isso pode ser percebido em notícias nais quais ela demonstra poder de síntese. Ela usa termos como "Em outras palavras”, "traduzindo", para explicar determinados temas, demonstrando ter certo domínio do assunto tratado.

Além disso, percebe-se, também, que a jornalista tem acesso a documentos específicos (documentos anexados a processos enviados ao Tribunal Superior Eleitoral; documentos relativos à defesa de políticos). Entretanto, a leitura da política que ela realiza 
resume-se a rumores sobre relações entre presidente e ministros (como, por exemplo, a relação do Presidente com Renan Calheiros, líder do PMDB no Senado6), ou a entender a política como um "jogo", em que cada partido ou político elabora estratégias bem definidas e intencionalmente calculadas.

Revelam-se, também, dessa forma, os anúncios da agenda do Presidente da República: jantares que ele teria dado em sua casa para se reunir com "aliados"; campanhas publicitárias do governo do Presidente Michel Temer sobre reforma da Previdência; nomeação de ministros, entre outros. Dessa forma, a cobertura jornalística do blog resumese à política institucional e nenhum outro tipo de fonte aparece como, por exemplo, associações ou sindicatos.

Quadro 3 - Informação política no Blog da Andréia Sadi

\begin{tabular}{|c|c|}
\hline \multicolumn{2}{|c|}{ “Jogo" político } \\
\hline $\begin{array}{c}\text { Relação com ministros/deputados: } \\
\text { da liderança do partido (PMDB) }\end{array}$ & “Ontem, Temer e ministros mapearam os votos infiéis e \\
traçaram a estratégia."
\end{tabular}

Fonte: Elaborado pelas autoras, com citações de Sadi (2017a, 2017b).

Sob o pretexto de se manter distante dos fatos e relatar de maneira objetiva, a jornalista acaba por perder sua autonomia profissional em relação às fontes.

\section{Considerações finais}

O artigo buscou entender a produção da informação política por meio de um blog de uma jornalista considerada especializada em política. Partimos de um questionamento amplo sobre a relação entre o blog ser um espaço dedicado exclusivamente à cobertura

\footnotetext{
6 No dia 5 de abril de 2017, a jornalista publica uma notícia em que afirma que a relação entre o Presidente da República, Michel Temer, e Renan Calheiros "nunca foi boa" e que, portanto, Temer quer "isolar Renan" das decisões do partido do qual ele faz parte (SADI, 2017a).
} 
política e o seu papel no questionamento das ações públicas. Os resultados apresentados questionam, entretanto, os valores tradicionais do jornalismo, como a busca pela pluralidade de vozes, uma vez que observamos:

a) predominância das declarações e das reações dos responsáveis políticos;

b) peso dos políticos na mise en distance dos fatos;

c) foco do artigos nos "bastidores" do governo e nas consequências das ações do presidente no "jogo" político entre "esquerda" e "direita";

d) questões políticas "personalizadas" na figura, principalmente, do Presidente Michel Temer. Como afirma Legavre (2005), a escrita da imprensa privilegia a mise en scène de personagens;

e) espaço dado a rumores, previsões futuras baseadas em declarações e especulações. A política tratada pelo blog diz respeito a um curto período de tempo: focaliza-se nos escândalos do momento sem necessariamente contextualizá-los;

f) as notícias revelam, por fim, o jogo de co-construção entre a jornalista e os assessores, ou seja, interdependências entre a jornalista e os interlocutores políticos e suas estratégias de comunicação. A jornalista segue, por exemplo, a agenda do presidente, e, muitas vezes, a notícia diz respeito a apenas um anúncio institucional, como o lançamento de uma campanha política. Portanto, na prática diária, os jornalistas não são tão independentes como afirmam, desempenhando, muitas vezes, um papel de divulgação das estratégias de comunicação das autoridades políticas.

Em conclusão, a análise revela que há dissonâncias entre os princípios que fundamentam a profissão jornalística e as notícias produzidas. Para além dessa constatação, a análise demonstra o processo de seleção e hierarquização na produção da informação política, na contemporaneidade, por uma das grandes empresas midiáticas do país. 0 artigo levanta, também, perspectivas futuras de reflexões sobre a pressão exercida pela lógica profissional e editorial na produção de informação. Contudo, é importante ressaltar que esses resultados inserem-se em uma perspectiva de uma pesquisa mais ampla que visa analisar outros blogs e compará-los. Além disso, seria interessante confrontar os resultados da análise a uma entrevista com a jornalista Andréia Sadi. Esse método permitiria compreender mais profundamente suas estratégias enquanto profissional e o peso das 
lógicas (comerciais, editoriais e profissionais) sobre a sua produção de notícia. As condições de produção e divulgação de notícias também exercem um impacto relevante na credibilidade jornalística.

\section{Financiamento}

Pesquisa financiada pela Coordenação de Aperfeiçoamento de Pessoal de Nível Superior (CAPES).

\section{Referências}

ALDE, Alessandra; ESCOBAR, Juliana; CHAGAS, Viktor. Febre dos blogs. Revista Famecos, Porto Alegre, v. 14, n. 33, p. 29-40, 2007.

ARENDT, Hannah. Qu'est-ce que la politique? Paris: Editions du Seuil, 1995.

ARISTOTE. Rhétorique. Paris: Pocket, 2007.

BERGER, Peter; LUCKMANN, Thomas. La construction sociale de la réalité. 3. éd. Paris: Armand Colin, 2012.

BOURDIEU, Pierre. Questions de sociologie. Paris: Les Editions de Minuit, 2002.

BRASIL. Código de ética dos jornalistas brasileiros. Brasília: Fenaj, 2007.

CARVALHO, Fernanda Cavassana de. A disputa presidencial de 2014 em portais de revistas brasileiras: análise comparativa entre editoria e blog na cobertura eleitoral de Veja e Cartacapital na Internet. 2016. Dissertação (Mestrado em Comunicação) Universidade Federal do Paraná, Curitiba, 2016.

DOMINGO, David; HEINONEN, Ari. Weblogs and Journalism: A Typology to Explore the Blurring Boundaries. Nordicom Review, Göteborgs, v. 1, n. 29, p. 3-15, 2008.

FOLETTO, Leonardo Feltrin. 0 blog jornalístico: definição e características na blogosesfera brasileira. 2009. Dissertação (Mestrado em Jornalismo) - Universidade Federal de Santa Catarina, Florianópolis, 2009.

G1. Andréia Sadi. G1, Rio de Janeiro, 27 out. 2017. Disponível em: <https://g1.globo.com/politica/blog/andreia-sadi/post/andreia-sadi.ghtml>. Acesso em: 27 abr. 2018.

GUAZINA, Liziane. 0 jornalismo que tem lado: o caso dos blogueiros brasileiros "progressistas". Brazilian Journalism Research, Brasília, v. 9, n. 2, p. 68-87, 2013. 
GUAZINA, Liziane. Quando cultura política e subcultura profissional jornalística andam de mãos dadas: a desconfiança na política em tempos de escândalos. In: HERMANN, Julian; GAUAZINA, Liziane; PEREIRA, Fábio (Orgs.). Novos questionamentos em mídia e política. Florianópolis: Insular, 2015. p. 43-73.

KARAM, Francisco Jose. A ética jornalística e o interesse público. Summus Editorial: 2004.

LE CAM, Florence, Histoires et filiations du terme 'weblogs' (1992-2003): Perspectives pour penser l'histoire de certaines pratiques sociales sur le web. Les Enjeux de l'information et de la communication, Grenoble, v. 2010, p. 97-120, 2010.

LE DÉSINTOX. Libération, Paris, [2018]. Disponível em :

<http://desintox.blogs.liberation.fr/>. Acesso em: 27 abr. 2018.

LEGAVRE, Jean-Baptiste. La politique par les médias, les élections du printemps $2004 \mathrm{au}$ prisme de la presse quotidienne. Questions de Communication, Lorraine, n. 8, p. 295-317, 2005 .

LEMIEUX, Cyril. Mauvaise presse. Paris: Editions Métaillé, 2000.

LIMA, Claudia do Carmo Nonato. Jornalistas, blogueiros, migrantes da comunicação. 2015. Tese (Doutorado em Ciências da Comunicação) - Universidade de São Paulo, São Paulo, 2015.

LISBOA, Silvia; BENNETTI, Marcia. O jornalismo como crença verdadeira e justificada. Brazilian Journalism Research, Brasília, v. 11, n. 2, p. 10-29, 2015.

MARCHETTI, Dominique. La fin d'un Monde? Les transformations du traitement de la «politique étrangère » dans les chaînes de télévision françaises grand public. In: ARNAUD, Lionel; GUINNET, Christine (Org.). Les frontières du politique. Rennes: PUR, 2005. p. 4977.

MIÈGE, Bernard. A sociedade tecida pela comunicação: Técnicas da informação e da comunicação entre inovação e enraizamento social. São Paulo: Paulus, 2009.

NEVEU, Erik. Métier politique: d'une institutionnalisation à une autre. In: LAGROYE, Jacques (org.). La politisation. Paris: Belin, 2003. p. 103-121.

NEVEU, Erik. Jornalismo sem jornalistas. Brazilian Journalism Research, Brasilia, v. 6, n. 1, p. 29-57, 2010.

NOBLAT, Ricardo. Blog do Noblat. 0 Globo, Rio de Janeiro, c2018. Disponível em: $<$ http://noblat.oglobo.globo.com/>. Acesso em: 4 de abr. 2018.

NOLLET, Jérémie. Les communicateurs des ministères, entre champs bureaucratique et journalistique. In: CHUPIN, Ivan; NOLLET, Jérémie (orgs.). Journalisme et Dépendances. Paris: L'Harmattan, 2006. p. 161-185. 
O GLOBO. É isso mesmo? O Globo, Rio de Janeiro, c2018. Disponível em: <https://blogs.oglobo.globo.com/eissomesmo/>. Acesso em: 27 abr. 2018.

PADIOLEAU, Jean-Gustave. Systèmes d'interaction et rhétoriques journalistiques. Sociologie du Travail, Paris, n. 3, p. 256-282, 1976.

PEREIRA, Fábio. Jornalistas e fontes e a construção da notícia política em Brasília. In: HERMANN, Julian; GUAZINA, Liziane; PEREIRA, Fábio (orgs.). Novos questionamentos em mídia e política. Florianópolis: Insular, 2015. p. 155 -172.

PEREIRA, Fábio; ADGHIRNI, Zélia. 0 jornalismo em tempos de mudanças estruturais. Intexto, Porto Alegre, v. 1, n. 24, p. 38-57, 2011.

QUADROS, Claudia Irene de; ROSA, Ana Paula da; VIEIRA, Josiany. Blogs e as transformações do Jornalismo. E-compós, [S.l.], v. 3, 2005.

RUELLAN, Denis. Le journalisme ou le professionnalisme du flou. Grenoble: PUG, 2007.

RUELLAN, Denis. Les « pro » du journalisme. De l'état au statut, la construction d'un espace professionnel. Rennes: PUR, 1997.

SADI, Andréia. Blog da Andréia Sadi. G1, Rio de Janeiro, c2018. Disponível em: <http://g1.globo.com/politica/blog/andreia-sadi/>. Acesso em: 27 abr. 2018.

SADI, Andréia. Para isolar Renan, Temer vai criar canal direto com senadores do PMDB. G1, Rio de Janeiro, 2017a. Blog da Andréia Sadi. Disponível em:

<http://g1.globo.com/politica/blog/andreia-sadi/post/para-isolar-renan-temer-quercanal-direto-com-senadores-do-pmdb.html>. Acesso em: 15 jan. 2018.

SADI, Andréia. Pressionado, Temer se fecha sobre novo ministro do STF. G1, Rio de Janeiro, 2017b. Blog da Andréia Sadi. Disponível em: <http://g1.globo.com/politica/blog/andreiasadi/post/pressionado-temer-se-fecha-sobre-novo-ministro-do-stf.html $>$. Acesso em: 15 jan. 2018.

SALLES, Chloë. Les blogs du Monde, des outils de management non-conventionnel. Les Enjeux de l'information et de la communication, Grenoble, n. 17, p. 63-73, 2016.

SATUF, Ivan. 0 dispositivo blog e as transformações no jornalismo. In: ENCONTRO DOS PROGRAMAS DE PÓS-GRADUAÇÃO EM COMUNICAÇÃO DE MINAS GERAIS, 1., 2008, Belo Horizonte. Anais... Belo Horizonte: PUC Minas, 2008. p. 1-14.

SCHLENSINGER, Philip. Repenser la sociologie du journalisme. Les stratégies de la source d'information et les limites du média-centrisme. Réseaux, Paris, n. 51, p. 75-98, 1992.

SENNE, Fábio José Novaes. Enquadrando a política sob a ótica do escândalo: uma análise da cobertura de três escândalos políticos midiáticos, a partir da perspectiva do enquadramento. 2009. Dissertação (Mestrado em Comunicação) - Universidade de Brasília, Brasília, 2009. 


\title{
The production of information in Brasilia: the backstage of politics in Andréia Sadi's blog
}

\begin{abstract}
The article is a partial result of the postdoctoral internship of one of the authors, with the objective of studying the production of political information in Brazilian blogs. The investigation came from the analysis of articles published in the blog of the journalist Andréia Sadi, GloboNews reporter. The analysis corresponds to 198 publications from three months (February, March and April) of 2017. In order to understand and characterize the relations of interdependence between journalists specialized in politics and politicians, the article supports its argument in a paradox: The increasing visibility of political journalism-mainly from the emergence of journalistic blogs-and the lack of political information revealed by recompositions that affect both the political and the journalistic fields. Among the results, the most important ones are the communication strategies of the advisory services, the news that favors the political "game" between "right-wing politics" and "left-wing politics". Moreover, the lack of reflection on politics, since the information produced essentially corresponds to the different reactions of political "opponents".
\end{abstract}

\section{Keywords}

Political information. Political journalists. Blog. Weblog. GloboNews.

Recebido em 15/07/2017

Aceito em 29/11/2017 